\title{
Spectroscopic Characterization of Miniaturized Atmospheric-Pressure dc Glow Discharge Generated in Contact with Flowing Small Size Liquid Cathode
}

\author{
Piotr Jamróz $\cdot$ Wiesław Żyrnicki
}

Received: 1 April 2011/ Accepted: 14 June 2011/Published online: 1 July 2011

(C) The Author(s) 2011. This article is published with open access at Springerlink.com

\begin{abstract}
The miniaturized atmospheric pressure glow discharge (APGD) generated between a solid electrode and a flowing small size liquid cathode (dimension $2 \mathrm{~mm}$ ) was investigated here using optical emission spectroscopy. The discharge was studied in an open air atmosphere, and the spectral characteristics of the plasma source was examined. Analysed APGD was operated at a discharge voltage of 1,100-1,700 V, a discharge current of $20 \mathrm{~mA}$ and gaps between a solid anode and a liquid cathode in the range from 0.5 to $3.5 \mathrm{~mm}$. The emission intensities of the main species were measured as a function of various experimental conditions, including the solution flow rate, the gap between the electrodes, and the concentration of hydrochloric acid. The excitation temperature, the vibrational temperatures calculated from $\mathrm{N}_{2}, \mathrm{OH}$, and $\mathrm{NO}$ bands, and the rotational temperatures determined from band of $\mathrm{OH}, \mathrm{N}_{2}$ and $\mathrm{NO}$, were found to be dependent on these experimental parameters. The electron number density was determined from the Stark broadening of $\mathrm{H}_{\beta}$ line. Additionally, the ionization temperature and degree were calculated using the Saha-Boltzmann equation, with the ion to atom ratio for magnesium (MgII/MgI). The results demonstrated that $T_{\text {exc }}(\mathrm{H}), T_{\text {vib }}\left(\mathrm{N}_{2}\right), T_{\text {vib }}(\mathrm{OH}), T_{\text {vib }}(\mathrm{NO})$ and $T_{\text {rot }}(\mathrm{OH})$ were well comparable $(\sim 3,800-4,200 \mathrm{~K})$ for selected plasma generation conditions (gap $\geq 2.5 \mathrm{~mm}$, $\mathrm{HCl}$ concentration $\left.\geq 0.1 \mathrm{~mol} \mathrm{~L}{ }^{-1}\right)$, while the rotational temperatures determined from band of $\mathrm{N}_{2}(\sim 1,700-2,100 \mathrm{~K})$ and band of $\mathrm{NO}(\sim 3,000 \mathrm{~K})$ were considerably lower. The electron number density was evaluated to be $(3.4-6.8) \times 10^{20} \mathrm{~m}^{-3}$ and the ionization temperature varied, throughout in the 4,900-5,200 $\mathrm{K}$ range.
\end{abstract}

Keywords Atmospheric pressure glow discharge - Optical emission spectrometry Plasma diagnostics · Liquid cathode · Miniaturized plasma source

P. Jamróz $(\bowtie) \cdot$ W. Żyrnicki

Faculty of Chemistry, Wroclaw University of Technology, Wybrzeze Stanislawa Wyspianskiego 27, 50-370 Wroclaw, Poland

e-mail: piotr.jamroz@pwr.wroc.pl 


\section{Introduction}

Atmospheric pressure glow discharges (APGD's) generated in contact with liquid are of great importance due to their potential applications in analytical spectrometry [1-5] as compact and low operating cost atomic emission micro-sources. These plasma sources may be also applied to the production of special kinds of materials (coatings, nanoparticles, etc.) $[6,7]$, to surface modification [7], to the purification of waste water from organic compounds [8-10], and to water sterilization [8, 9].

Usually the generation of the APGD between a solid anode and a liquid cathode requires application of a dc high voltage [10-14]. Stable APGDs with liquid electrodes have been generated by applying voltages between 0.4 and $1.8 \mathrm{kV}$ and currents between 5 and $150 \mathrm{~mA}$, over gaps ranging from 0.2 to $5 \mathrm{~mm}$ in the air atmosphere $[7,15,17,18]$. On the other hand, by using a miniature argon or helium gas flow instead of a solid rod anode, stable glow discharge has been observed for gaps of up to $20 \mathrm{~mm}$ between the anode and the liquid cathode [17]. Stable APGD was also generated in other gas atmospheres like $\mathrm{N}_{2}$, $\mathrm{N}_{2} \mathrm{O}, \mathrm{CO}_{2}$ [15].

Recently, APGD plasmas with various liquid electrodes have been studied at different currents and distances from the liquid electrode [11-26], while the other plasma generation parameters were faintly investigated. Nevertheless, the phenomena of glow discharge generated at atmospheric pressure are still poorly understood. The emission and electrical properties of atmospheric pressure glow discharges generated between a metal pin electrode and surface of tap water (working as a cathode or anode) were investigated by Bruggeman et al. [11] as a function of discharge current (7.5-30 mA) and of distance from the cathode liquid surface. A cathode fall, a negative glow, a Faraday dark space, a positive column and an anode glow were identified in the discharge for the liquid electrode-pin electrode system [11, 14, 21] (Fig. 1). Additionally, Bruggeman et al. [11] found that rotational temperatures of $\mathrm{N}_{2}$ and $\mathrm{OH}$ were identical and equal to $3,250 \mathrm{~K}$ in the anode glow region (positive column). The cathode voltage drop, the electric field strength, and the vibrational and rotational temperatures of $\mathrm{N}_{2}$ were studied by Titov et al. $[12,13]$ as a function of discharge current (10-50 mA) for distilled water and for aqueous solutions of $\mathrm{HNO}_{3}, \mathrm{KCl}, \mathrm{KBr}$ and $\mathrm{KI}$. The plasma parameters, i.e., the vibrational and rotational temperatures of $\mathrm{N}_{2}(\sim 4,200$ and $\sim 2,100 \mathrm{~K}$, respectively), indicated that this atmospheric pressure glow discharge was a non-equilibrium system. The spatial distribution of the $\mathrm{OH}$ rotational temperature $(4,000-8,000 \mathrm{~K})$, the $\mathrm{Cu}$ excitation temperature $(5,500-7,500 \mathrm{~K})$ and the $\mathrm{OH}$ and $\mathrm{N}_{2}$ species emission intensities were reported by Cservalvi et al. in an electrolyte cathode—solid anode discharge (ELCAD) source [14]. In other work, enhanced metal emission intensities were observed in a liquid cathode containing hydrochloric acid [24]. The Fe excitation temperature and the $\mathrm{OH}$ rotational temperature as well as emission intensities of the main species were investigated by Webb et al. [2, 25] as a function of distance from the liquid cathode. Maximum temperatures and emission intensities were observed near the cathode region. Recently, Bruggeman et al. [22] reported the rotational temperatures of $\mathrm{OH}$ and $\mathrm{N}_{2}$, the electron number density and the $\mathrm{H}$ excitation temperature achieved using distilled water and a solution of $\mathrm{NaOH}$ and $\mathrm{NaCl}$ as liquid cathodes. These parameters were studied as a function of the discharge current, the solution conductivity and the distance from the cathode. The $\mathrm{OH}$ rotational temperature $(3,200-3,750 \mathrm{~K})$ was higher than the $\mathrm{N}_{2}$ rotational temperature $(2,500-2,750 \mathrm{~K})$, while the electron number density and the $\mathrm{H}$ excitation temperature were $(5.5-8.0) \times 10^{14} \mathrm{~cm}^{-3}$ and 5,750-7,250 K, respectively. Concentrations of $\mathrm{OH}$ radicals and the $\mathrm{OH}$ rotational temperature were measured Nikiforov et al. [26] as a function of discharge current, by means of laser induced 
Fig. 1 The schematic diagram of APGD generated in contact with liquid cathode

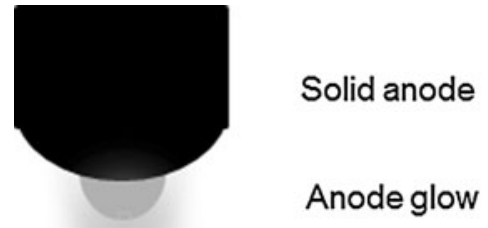

Positive column

Faraday dark space

Negative glow

Cathode fall

Liquid cathode

fluorescence (LIF) technique. They found that $\mathrm{OH}$ rotational temperature was in the range $2,850-3,250 \mathrm{~K}$, while the concentrations of $\mathrm{OH}$ were relative high $\left(10^{21}-10^{22} \mathrm{~m}^{-3}\right)$.

The main aim of this work was the spectroscopic characterization of miniaturized plasma source operated in an open air atmosphere between solid anode and a new construction of liquid cathode. As a small size liquid cathode the solution of hydrochloric acid spiked with Mg ions was applied. Various plasma parameters were measured at different experimental conditions. Investigated plasma parameters included the ionization, excitation, vibrational and rotational temperatures derived from various species, as well as electron number density. Experimental variables were the flow ratio of solution, the gap between electrodes, and the concentration of hydrochloric acid. In addition, we investigated the plasma equilibrium. Additionally, the range of plasma stability was described. It was found, that it is possible to generate stable plasma with flow of electrolyte and without, i.e., between solid anode and graphite tube. Advantageously, in this work a stable micro glow discharge was obtained at a lower solution uptake $\left(0.6 \mathrm{~mL} \mathrm{~min}^{-1}\right)$ than it has usually been reported in previous studies.

\section{Experimental Set-Up}

A schematic diagram of the experimental setup is presented Fig. 2. The construction of the plasma device developed and used here was quite different from this described by Cservalvi et al. [14, 24] and Webb et al. [2, 25]. In the construction proposed by these authors the electrolyte solution was introduced to the plasma by means of quartz tube and the overflow electrolyte from quartz tube (thin films of electrolyte on the outer parts of quartz tube) served as an electrical connection between plasma and the solution in the reservoir and consequently with the electrode. According to Mezei et al. [5], such the 


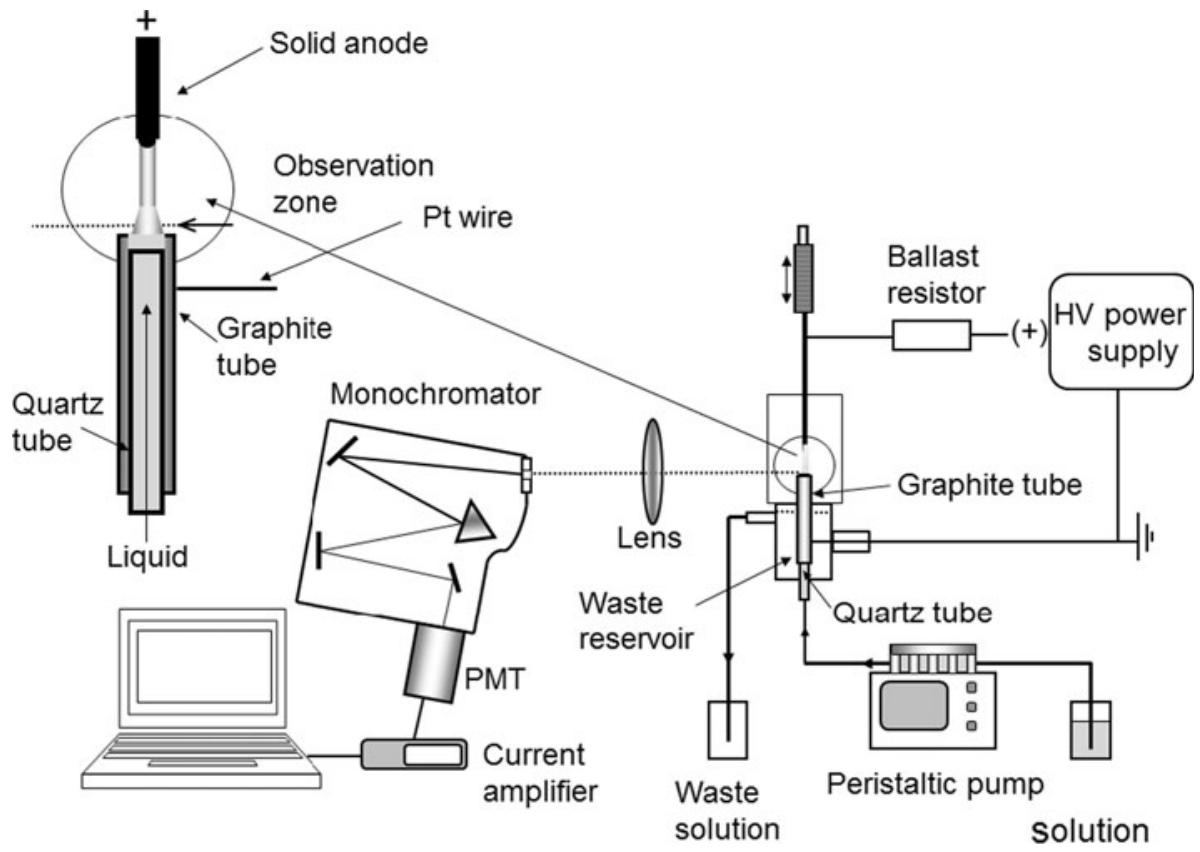

Fig. 2 The experimental setup (not to scale)

liquid cathode needed the higher flow rate of solutions in order to maintain electrical contact with electrode and plasma, and in consequence it did not work properly without flowing solution. Additionally, higher current was necessary and these devices could be more sensitive to instabilities for instance a presence of gases in the solution.

In the plasma device construction developed by us, the glow discharge was generated between a molybdenum rod anode and a small size flowing liquid cathode in an open air atmosphere. In order to improve the electrical contact with the electrolyte solution, an additional graphite tube was applied (Fig. 2). At the top of the graphite tube (4 mm) it was encountered with the electrolyte. In contrast with other studies described in a recent review paper [5], we found that a lower sample uptake (range of flow rates from 0.60 to $3.20 \mathrm{~mL} \mathrm{~min}^{-1}$ ) was required to maintain a stable glow discharge at atmospheric pressure. It was also possible generate stable plasma without liquid flow, i.e., between solid anode and graphite tube. This plasma device construction proposed here is considerably less sensitive for any instabilities and interferences than the former devices.

The discharge was powered by a dc high voltage power supply. A positive potential was supplied to the anode, while a grounded platinum wire was used to make electrical contact with the graphite tube and consequently with the electrolyte. A discharge current equal to $20 \mathrm{~mA}$ was used for all experiments. A $20 \mathrm{k} \Omega$ ballast resistor was connected to the anode positive output to stabilize the discharge current. The distance between the anode and the cathode was adjusted using a micrometer screw attached to the solid anode. As an electrolyte, the solution of $\mathrm{HCl}$ spiked with $\mathrm{Mg}$ ions was applied. The liquid sample was introduced into the plasma zone through a quartz-graphite tube, with an inner diameter of $2 \mathrm{~mm}$, using a Jobin-Yvon peristaltic pump. The diameter of graphite tube was limited the 
Table 1 Experimental conditions

\begin{tabular}{ll}
\hline Type of discharge & dc-APGD \\
Current & $20 \mathrm{~mA}$ \\
Voltage & $1,100-1,700 \mathrm{~V}$ \\
Ballast resistor & $20 \mathrm{k} \Omega$ \\
Atmosphere/pressure & Open air/atmospheric pressure \\
Gap between electrodes & $0.5-4.0 \mathrm{~mm}$ \\
Electrolyte flow rate & $0.60-3.2 \mathrm{~mL} \mathrm{~min}{ }^{-1}$ \\
Liquid cathode & Solution of HCl, spiked with Mg ions, \\
& maximum diameter $2 \mathrm{~mm}$ \\
\hline
\end{tabular}

dimension of cathode and consequently the plasma dimension. Working solution of $\mathrm{Mg}$ ions $\left(10 \mu \mathrm{g} \mathrm{mL}^{-1}\right)$ was prepared from a single stock solution (Merck, 1,000 $\mu \mathrm{g} \mathrm{mL}^{-1}$ ) by dilution with twice-distilled water. The aqueous $\mathrm{Mg}$ solutions were acidized using hydrochloric acid ( $\mathrm{HCl}, \mathrm{POCH}$ Gliwice, analytical grade). The addition of $\mathrm{HCl}$ was necessary to improve the solution conductivity. The $\mathrm{HCl}$ concentrations varied from 0.01 to $1.0 \mathrm{~mol} \mathrm{~L}{ }^{-1}$. The solution overflows from the quartz-graphite tube was collected in the waste reservoir. A summary of the experimental plasma excitation conditions is shown in Table 1.

A JY TRIAX 320 scanning monochromator (grating 1,200 grooves $\mathrm{mm}^{-1}$, blazed at $250 \mathrm{~nm}$ ) was used with a Hamamatsu R-928 photomultiplier biased at $-700 \mathrm{~V}$, to measure the emission coming from the plasma over the range from 200 to $850 \mathrm{~nm}$. The output signal of the photomultiplier was amplified using a JY SpecAcq2 system. The SpectraMax/ 32 software was used for data processing and collecting. Plasma emission was measured near the liquid cathode region. A quartz achromatic lens $(f=75.6$, diameter 2 ") was used to project the plasma radiation onto the entrance slit of the monochromator. Calibration of the whole optical system was undertaken with a CL2 halogen lamp (Bentham), working at 8.5 A, 17.2 V, with a known spectral emissivity (Protection Engineering Ltd. certificate of radiation).

\section{Experimental Results and Discussion}

\section{Emission Spectra of Atmospheric Pressure dc Glow Discharge}

Over all experimental conditions, spectra emitted by the atmospheric pressure dc glow discharge consisted of molecular bands of $\mathrm{OH}, \mathrm{N}_{2}, \mathrm{NH}$ and $\mathrm{NO}$ (see Fig. 3a-c), and atomic lines of hydrogen $\left(\mathrm{H}_{\alpha}, \mathrm{H}_{\beta}\right)$ and oxygen $\mathrm{O}$ I. The hydrogen line, $\mathrm{H}_{\gamma}$ at $434.14 \mathrm{~nm}$, was not clearly distinguished due to the overlapping by the band of $\mathrm{N}_{2}(0-4)$ with the bandhead at $434.36 \mathrm{~nm}$. Details of the molecular and atomic species identified as well as their excitation energies are presented in Table 2.

The spectral lines resulted from excitation processes of species originating either from the saturated water vapour and/or from the surrounding air atmosphere. If the water in the system was replaced by a solution containing $\mathrm{Mg}$ ions, additionally strong atomic line of the $\mathrm{Mg} \mathrm{I}$ at $285.21 \mathrm{~nm}$, was observed. We also detected and measured weak lines of ionized magnesium, i.e., Mg II at $279.55 \mathrm{~nm}$ and $\mathrm{Mg}$ II at $280.257 \mathrm{~nm}$ (see Fig. 2b). As can be seen in the Table 2, the maximum energy of excited states of species was up to $13 \mathrm{eV}$. 

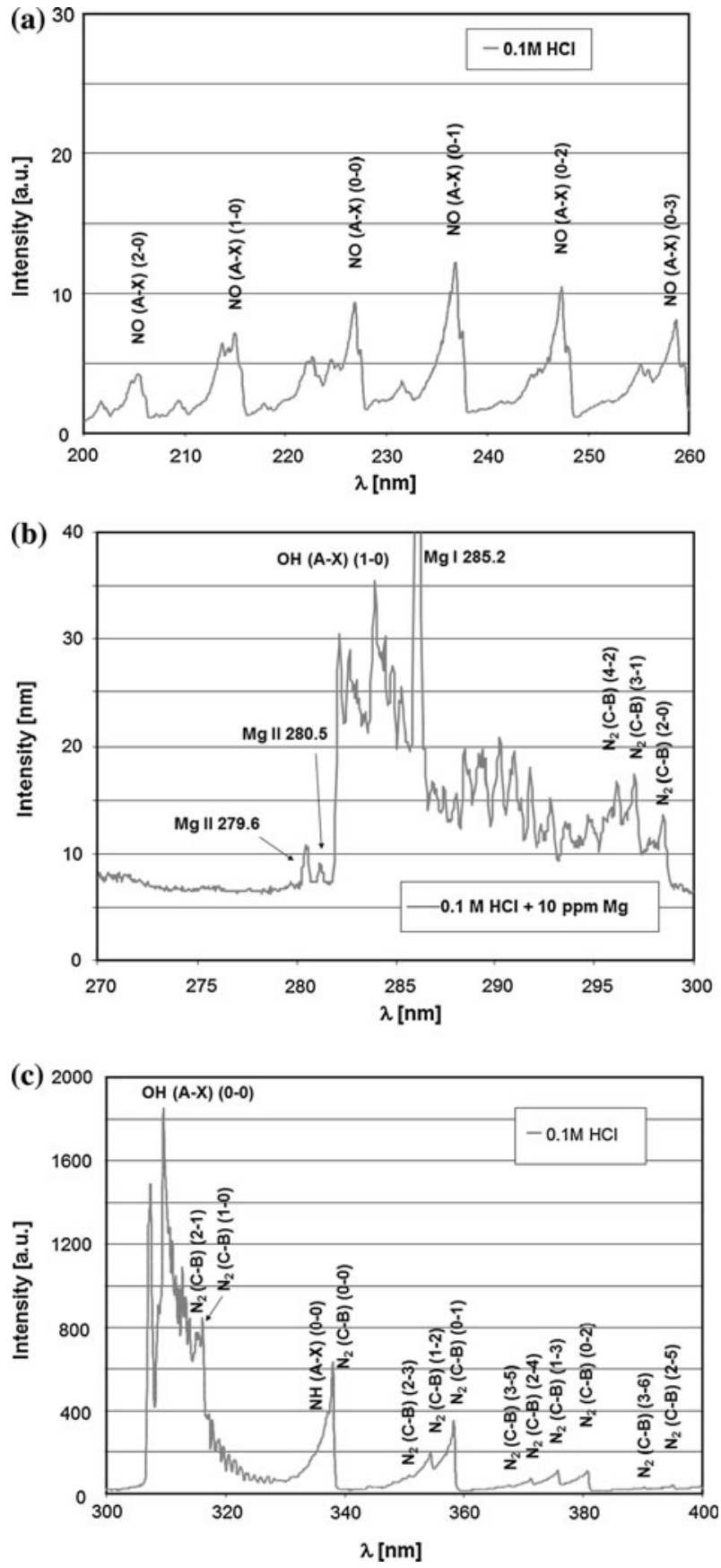

Fig. 3 The emission spectrum of APGD over the range a 200-260 nm, b 270-300 nm and c 300-400 nm (0.1 $\mathrm{M} \mathrm{HCl}$ spiked with $10 \mathrm{ppm} \mathrm{Mg}$ ions) 
Table 2 Atomic and molecular species identified in the region near the liquid cathode

\begin{tabular}{lll}
\hline Species & Emission spectra & Excitation energy \\
\hline $\mathrm{N}_{2}$ & Numerous bands of the $\mathrm{C}^{3} \Pi_{\mathrm{u}}-\mathrm{B}^{3} \Pi_{\mathrm{g}}$ system & $\sim 11.2-11.9 \mathrm{eV}$ \\
$\mathrm{OH}$ & Bands of the $\mathrm{A}^{2} \Sigma-\mathrm{X}^{2} \Pi$ system $(0-0)(1-0)(2-0)$ & $\sim 4.1 \mathrm{eV}$ \\
$\mathrm{NO}$ & Numerous bands of the $\gamma$-system $\left(\mathrm{A}^{2} \Sigma^{+}-\mathrm{X}^{2} \Pi\right)$ & $\sim 5.5-6.5 \mathrm{eV}$ \\
$\mathrm{NH}$ & Band of the $\mathrm{A}^{3} \Pi-\mathrm{X}^{3} \Sigma^{-}$system $(0-0)$ at $336.0 \mathrm{~nm}$ & $\sim 3.7 \mathrm{eV}$ \\
$\mathrm{H}$ & Lines at $486.1 \mathrm{~nm}\left(\mathrm{H}_{\beta}\right)$ and $656.2 \mathrm{~nm}\left(\mathrm{H}_{\alpha}\right)$ & $12.74 \mathrm{eV} ; 12.09 \mathrm{eV}$ \\
$\mathrm{O} \mathrm{I}$ & Lines at 777.2 and $844.6 \mathrm{~nm}$ & $10.74 ; 10.99 \mathrm{eV}$ \\
$\mathrm{Mg} \mathrm{I}$ & Line at $285.21 \mathrm{~nm}$ & $4.34 \mathrm{eV}$ \\
$\mathrm{Mg} \mathrm{II}$ & Lines at 279.55 and $280.26 \mathrm{~nm}$ & $12.07 \mathrm{eV}$ \\
\hline
\end{tabular}

The presence of magnesium atoms (or ions) in the plasma zone can be attributed to plasma sputtering of the water surface, similarly to the plasma sputtering processes in low pressure glow discharge, according to [18, 19]. Generally, emission intensities of atomic and ionic $\mathrm{Mg}$ lines decreased with lowering concentration of $\mathrm{HCl}$ in solution. By contrast, the decrease of $\mathrm{HCl}$ concentration in solution (and consequently, the decrease of the solution conductivity) caused the increase of the burning voltage from 1,300 to 1,700 V. A similar dependence was noted by Mezei et al. in a ELCAD source [5]. At the $\mathrm{HCl}$ concentration of $0.01 \mathrm{~mol} \mathrm{~L}^{-1}$, the $\mathrm{Mg}$ atomic spectral line was very weak and the $\mathrm{Mg}$ II lines were not excited. A similar effect was also observed by Cserfalvi and Mezei [18], who also observed the metal atomic lines when the solution $\mathrm{pH}$ was higher than 2.5. In this work, the emission ion to atom ratio for $\mathrm{Mg}(\mathrm{MgII} / \mathrm{MgI})$ was found to be between 0.027 and 0.080 . It is two orders of magnitude lower than in the inductively coupled plasma (ICP) source working at atmospheric pressure [27]. The maximum value of the ion to atom ratio for $\mathrm{Mg},(0.080)$, was observed using a solution containing $1.0 \mathrm{~mol} \mathrm{~L}^{-1} \mathrm{HCl}$.

In contrast to others reports on emission spectra of APGD plasmas generated using significantly higher currents and slightly lower voltage [11, 25], we did not observe any molecular bands of $\mathrm{N}_{2}{ }^{+}$or any ionic lines of oxygen (O II) in the near cathode region. The excited states of ionized molecular nitrogen $\left(\mathrm{N}_{2}{ }^{+}\right)$and ionized oxygen $\left(\mathrm{O}^{+}\right)$require threshold energies of approximately $\sim 18$ and $\sim 25-35 \mathrm{eV}$, respectively. Anyway, these values seem to be large compared with the energies of electrons or other high energy species present in glow discharge plasmas at atmospheric pressure [5, 13].

\section{The Behavior of Active Plasma Species}

Emission from plasma was monitored versus experimental parameters, including solution flow rate, gap size (length of separation between the solid anode and the liquid cathode) and the $\mathrm{HCl}$ concentration in solution.

The emission intensities of $\mathrm{OH}$ (head band at $309.5 \mathrm{~nm}$ ), $\mathrm{N}_{2}$ (head band at $337.1 \mathrm{~nm}$ ), $\mathrm{H}_{\beta}$ (line at $486.1 \mathrm{~nm}$ ), O I (line at $777.2 \mathrm{~nm}$ ) and $\mathrm{Mg}$ I (line at $285.2 \mathrm{~nm}$ ) were chosen as representatives to investigate the behavior of active plasma components. The emission of these species as a function of the size of the gap between the cathode and anode was shown in Fig. 4a. The distance between the solid anode and the liquid water surface (working as a cathode) was changed from 0.5 to $3.5 \mathrm{~mm}$. Outside of this range, for gaps greater than $4.0 \mathrm{~mm}$ or less than $0.5 \mathrm{~mm}$, the discharge was unstable and was therefore not investigated. Generally, intensities of $\mathrm{OH}, \mathrm{N}_{2}$ and $\mathrm{H}$ increased with the gap size and maximum 
intensities were observed at the gap of $2.5 \mathrm{~mm}$. For the $2.5 \mathrm{~mm}$ gap, the volume of plasma and the diameter of the cathode spot were estimated to be $\sim 6 \mu \mathrm{L}$ and $\sim 1.5 \mathrm{~mm}$, respectively. The growth in distance between the solid anode and the liquid cathode required a commensurate increase in applied voltage, from 1,100 to $1,700 \mathrm{~V}$, changing the discharge power from 22 to 34 Watts. In contrast, the Mg I intensity decreased with an increasing gap between the electrodes (Fig. 4a). It was probably associated with the spreading of desolvated $\mathrm{Mg}$ atoms as the distance between electrodes grew. For small gap sizes $(0.5-1.0 \mathrm{~mm})$ only the negative glow was visible. The positive column appeared and grew for gaps larger than $1.5 \mathrm{~mm}$. Usually, the emission of the metal lines was the strongest in the near cathode region (negative glow), but weak metal intensities were also observed in the near anode region, i.e., in the positive column [25].

Raising the solution flow rate from 0.60 to $3.2 \mathrm{~mL} \mathrm{~min}^{-1}$ led to a linear increase in the emission intensities of $\mathrm{OH}, \mathrm{H}, \mathrm{O}$ and $\mathrm{N}_{2}$ species (Fig. 4b), while the intensity of the $\mathrm{Mg} \mathrm{I}$ line decreased and was lowest for solution flow rates of $1.9-2.3 \mathrm{~mL} \mathrm{~min}^{-1}$. A similar effect was also observed by Shaltout [3] for the Ca I emission line in a dc microplasma source, generated at the following conditions: current $20-80 \mathrm{~mA}$, voltage $500 \mathrm{~V}$, gap $0.5-2 \mathrm{~mm}$. The decrease in the Mg I emission along with growing solution flow rate may also be a consequence of additional water vaporization. The presence of additional water (or products coming from water) may reduce the energy and number of free electrons responsible for the excitation of $\mathrm{Mg}$ atoms.

Intensities of the main species were also monitored as a function of $\mathrm{HCl}$ concentration. The intensities of $\mathrm{OH}, \mathrm{N}_{2}, \mathrm{Mg} \mathrm{I}$ and $\mathrm{O}$ I increased with the growth of the $\mathrm{HCl}$ concentration, while the emission intensity of the $\mathrm{H}$ emission line changed in a different manner (Fig. 4c). The dissociation of water vapour $\left(\mathrm{H}_{2} \mathrm{O}+\mathrm{e}=\mathrm{OH}+\mathrm{H}+\mathrm{e}\right)$ and dissociative recombination of $\mathrm{H}_{2} \mathrm{O}^{+}$ions $\left(\mathrm{H}_{2} \mathrm{O}^{+}+\mathrm{e}=\mathrm{OH}+\mathrm{H}\right)$ were found to be the dominant processes for the production of $\mathrm{H}$ and $\mathrm{OH}$ species in the central part of the plasma [5]. However, the difference in behavior of the $\mathrm{OH}$ and $\mathrm{H}$ emission intensities as a function of experimental conditions can be treated as evidence for the presence of a multichannel process in the region near the liquid cathode. The excited state of nitrogen, $\mathrm{N}_{2}(\mathrm{C})$, was produced by electron impact excitation of nitrogen in the surrounding air. In contrast, a stepwise reaction consisting of the dissociation of molecular oxygen followed by electron impact excitation of oxygen atoms was probably the main mechanism responsible for producing excited states of atomic oxygen [13]. An alternative process, dissociative excitation of water by electron impact resulting in excited states of $\mathrm{O}$, seems to be unlikely
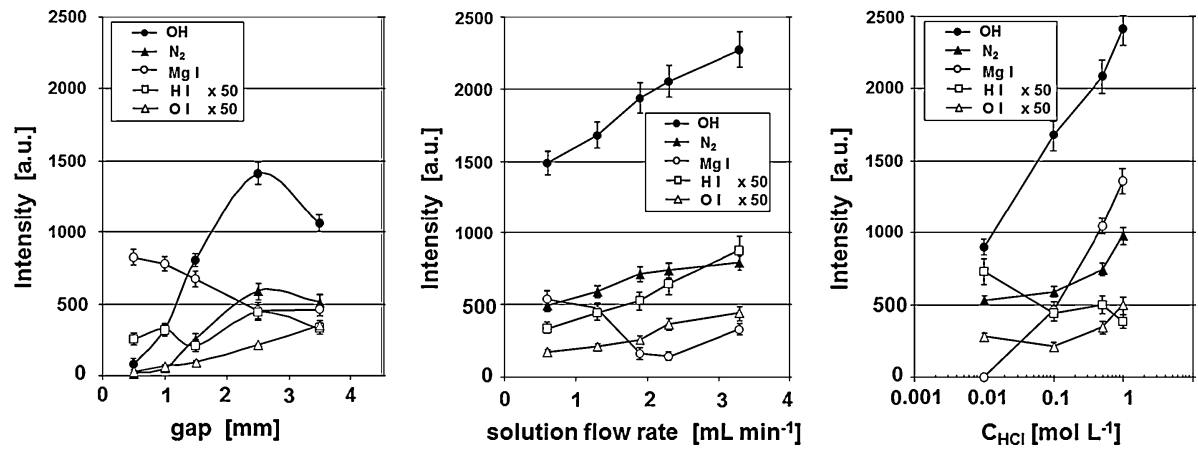

Fig. 4 The intensities of $\mathrm{OH}, \mathrm{N}_{2}, \mathrm{Mg}, \mathrm{H}$, and $\mathrm{O}$ versus the length of the gap between the solid anode and the liquid cathode, the solution flow rate, and the concentration of $\mathrm{HCl}$ in solution 
due to very high energy thresholds (17.6 eV) [11]. The growth of $\mathrm{Mg}$ I intensity with $\mathrm{HCl}$ concentration is probably due to an enhanced sputtering rates of the liquid cathode at higher $\mathrm{HCl}$ solution concentrations.

\section{Plasma Parameters}

Plasma temperatures, i.e., the ionization, excitation, vibrational, and rotational temperatures, and electron number density are very important parameters for description of a plasma source. The plasma temperatures of different species, permit a characterization of plasma equilibrium phenomena. Additionally, knowledge of the electron number density plays an important role in understanding the processes (excitation, ionization, etc.), which exist in a plasma source.

The Excitation, Vibrational and Rotational Temperatures in the APGD Source

The excitation temperature ( $T_{\text {exc }}$ ) was determined using the two-line intensity ratio method [22]. Two prominent lines of hydrogen: $\mathrm{H}_{\alpha}$ at $656.28 \mathrm{~nm}$ and $\mathrm{H}_{\beta}$ at $486.13 \mathrm{~nm}$ were applied. The vibrational temperature determined from $\mathrm{N}_{2}$ and $\mathrm{NO}$ bands $\left[T_{\mathrm{vib}}\left(\mathrm{N}_{2}\right)\right.$, $\left.T_{\mathrm{vib}}(\mathrm{NO})\right]$ were calculated by the Boltzmann plot method. For $\mathrm{N}_{2}$, the four bands of the $\mathrm{C}^{3} \Pi_{\mathrm{u}}-\mathrm{B}^{3} \Pi_{\mathrm{g}}$ system, i.e., (0-2); (1-3); (2-4); (3-5), were used. For NO, the (0-0); (1-0) and (2-0) bands of $\mathrm{A}^{2} \Sigma^{+}-\mathrm{X}^{2} \Pi$ system, were employed. The linearity of the Boltzmann plot (see Fig. 5) indicates that the vibrational levels of $\mathrm{N}_{2}$ follow the Boltzmann distribution. A similar dependence was observed for the vibrational levels of NO.

The monochromator resolution was low therefore, the rotational temperatures $\left(T_{\text {rot }}\right)$ were determined from the unresolved rotational structures of $\mathrm{OH}\left(\mathrm{A}^{2} \Sigma^{+}, \mathrm{v},=0 \rightarrow \mathrm{X}^{2} \Pi\right.$;

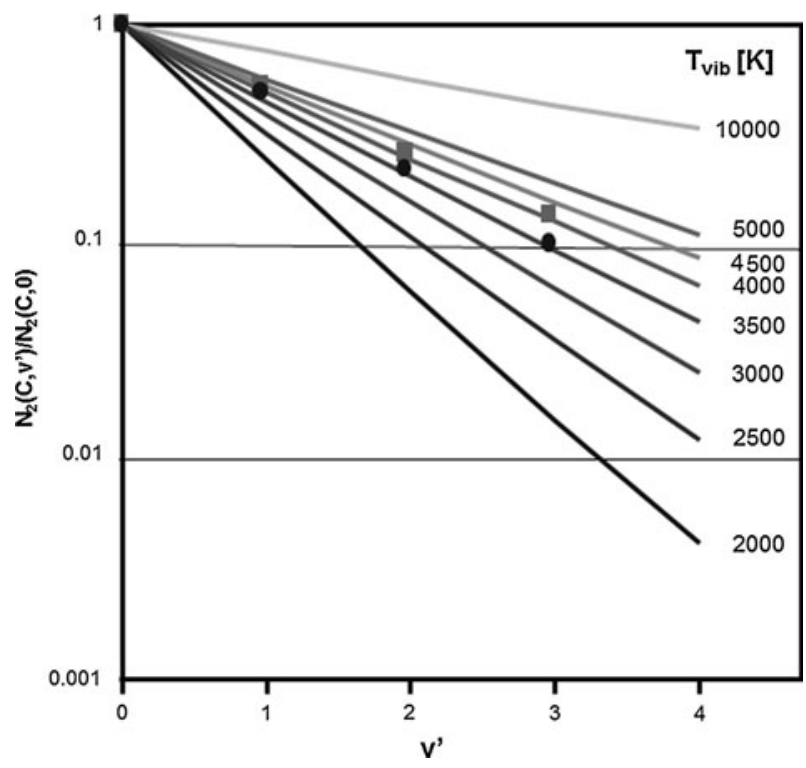

Fig. 5 The distribution of the $\mathrm{N}_{2}\left(\mathrm{C}, \mathrm{v}^{\prime}\right)$ population normalized to the $\mathrm{N}_{2}(\mathrm{C}, 0)$ population, over vibrational temperatures ranging from 2,000 to $10,000 \mathrm{~K}$, for solution uptake values of $0.6 \mathrm{~mL} \mathrm{~min}{ }^{-1}$ (circles) and $1.9 \mathrm{~mL} \mathrm{~min}^{-1}$ (squares) using $0.1 \mathrm{~mol} \mathrm{~L}^{-1} \mathrm{HCl}$ 
$\mathrm{v} "=0$, in the range $306-310 \mathrm{~nm}), \mathrm{N}_{2}\left(\mathrm{C}^{3} \Pi_{\mathrm{u}}, \mathrm{v}^{\prime}=0 \rightarrow \mathrm{B}^{3} \Pi_{\mathrm{g}} ; \mathrm{v}^{\prime}=2\right.$, in the range $376-380 \mathrm{~nm})$ and $\mathrm{NO}\left(\mathrm{A}^{2} \Sigma^{+}, \mathrm{v}^{\prime}=0 \rightarrow \mathrm{X}^{2} \Pi\right.$; $\mathrm{v}^{\prime \prime}=1$, in the range $\left.232-237 \mathrm{~nm}\right)$ by comparison between experimental and simulated spectra method. In the case of $\mathrm{OH}$ only the lower rotational levels were taken into account. The rotational temperature was often determined by means of low resolution emission spectra of $\mathrm{OH}$ band (e.g., [11, 14]). The shape of unresolved parts of $\mathrm{OH}$ spectra in the range $306-310 \mathrm{~nm}$ is sensitive to plasma temperature variations and thus may be used for the temperature determination. A similar dependence was observed in case of $\mathrm{N}_{2}$ and NO bands. The LIFBASE [28] and SpecAir [29] computer programs were applied to simulate the emission band spectra of $\mathrm{OH}(\mathrm{A}-\mathrm{X})$, $\mathrm{N}_{2}(\mathrm{C}-\mathrm{B})$ and $\mathrm{NO}(\mathrm{A}-\mathrm{X})$ for various rotational temperatures. A similar procedure was also applied to estimate the vibrational temperature determined from bands of $\mathrm{OH}$. The spectra of two bands of $\mathrm{OH},(0-0)$ and (1-0) were simulated at various vibrational temperatures and compared with experimental data. The spectroscopic constants of $\mathrm{H}, \mathrm{Mg}$ I, and $\mathrm{Mg}$ II were taken from the NIST Atomic Spectra Database [30]. For molecular $\mathrm{N}_{2}$, the spectroscopic constants were obtained from tables as reported by Lofthus et al. [31]. The uncertainties of the temperature measurements were calculated to be $\sim 15,2-10,2-8$ and $2-10 \%$ for the $T_{\text {exc }}(\mathrm{H}), T_{\mathrm{vib}}\left(\mathrm{N}_{2}\right), T_{\mathrm{vib}}(\mathrm{NO})$, and rotational temperatures respectively. Excitation, vibrational and rotational temperatures were measured as a function of the solution flow rate, the electrode gap size and the $\mathrm{HCl}$ concentration (Figs. 6, 7, 8).

As shown in Fig. 5, an increase of solution flow rate from 0.6 to $3.2 \mathrm{~mL} \mathrm{~min}^{-1}$ resulted in a growth of temperatures. The vibrational temperature determined from $\mathrm{N}_{2}$ bands changed from 3,400 to $4,600 \mathrm{~K}$ and the excitation temperature from 3,900 to 4,300 $\mathrm{K}$. The $T_{\text {rot }}(\mathrm{OH})$ and $T_{\text {rot }}\left(\mathrm{N}_{2}\right)$ depended slightly on the solution flow rate and varied from 3,600 to 4,000 $\mathrm{K}$ and 1,900-2,100 K, respectively (Fig. 6). The maximum values of the vibrational and excitation temperatures $(\sim 4,200 \mathrm{~K})$ were obtained for a gap equal to $1.5 \mathrm{~mm}$ (Fig. 7). For small gap sizes $(0.5-1 \mathrm{~mm})$ the excitation, vibrational and rotational temperatures

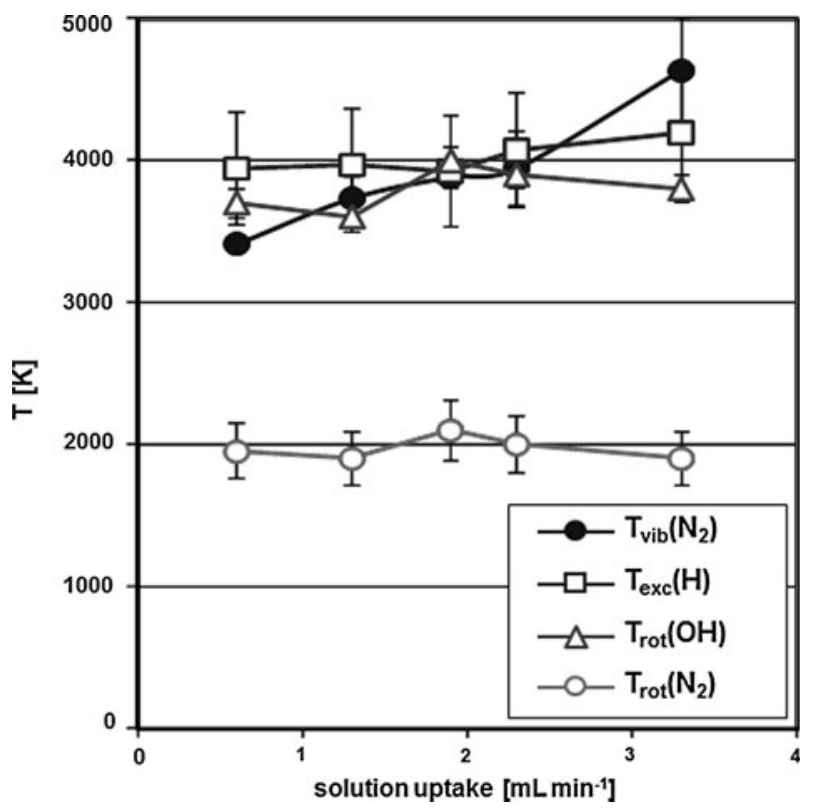

Fig. 6 The excitation, vibrational and rotational temperatures as a function of solution flow rate 


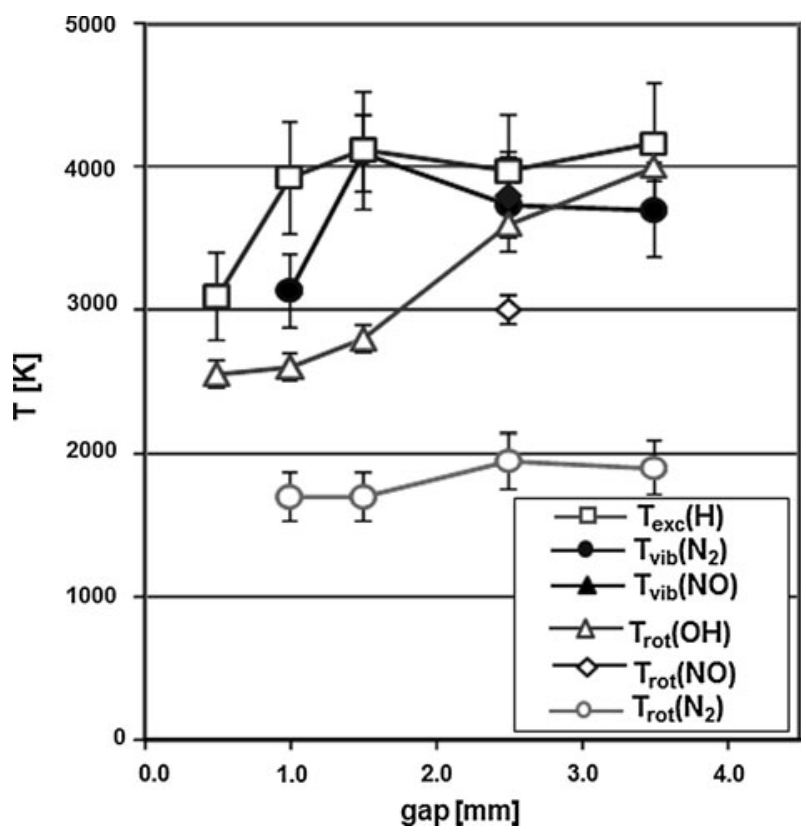

Fig. 7 Changes in the excitation, vibrational and rotational temperatures as a function of the size of the gap between the solid anode and the liquid cathode $\left(0.1 \mathrm{~mol} \mathrm{~L}^{-1} \mathrm{HCl}\right)$

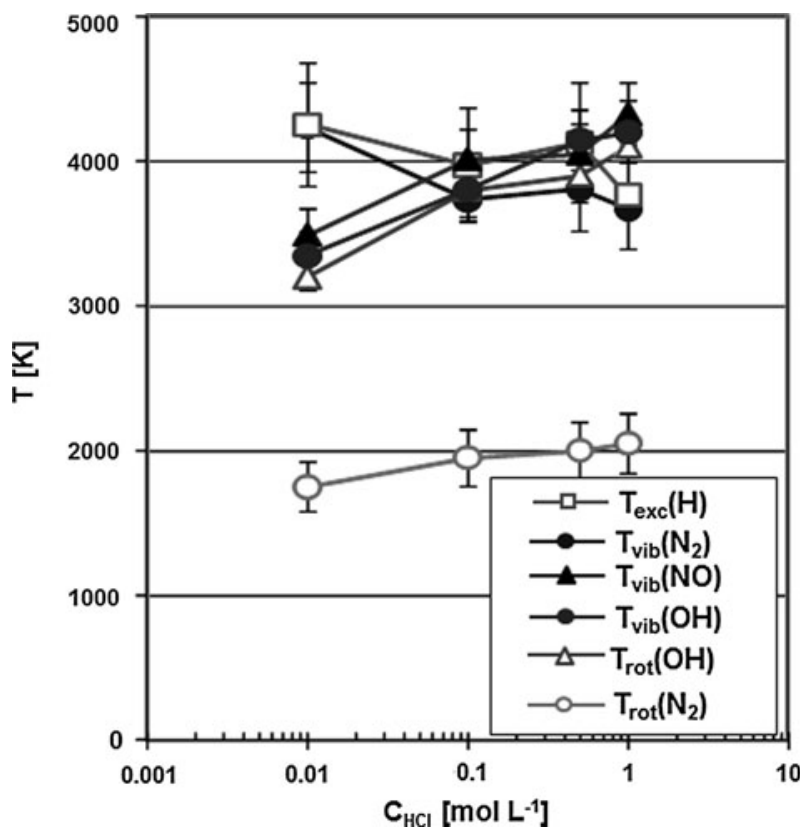

Fig. 8 The influence of $\mathrm{HCl}$ concentration on the plasma species temperatures 
were the lowest. The increase in the gap between electrodes caused a growth in these temperatures. The most significant change was noted for $T_{\text {rot }}(\mathrm{OH})$, namely from 2,700 to $4,000 \mathrm{~K}$. This was probably associated with an increase of the discharge power from 22 to 34 Watts, especially taking into account that water vapour is a carrier medium. A similar effect was observed by Webb et al. [25] for the rotational temperature (from 2,700 to $3,200 \mathrm{~K}$ ). The gap size only slightly affected the $T_{\text {rot }}\left(\mathrm{N}_{2}\right)$ (changes in the range $\sim 1,700-1,900 \mathrm{~K}$ ). Differences in the rotational temperatures indicate that mechanisms of the excitation process of these molecules are different. Changing the $\mathrm{HCl}$ concentration from 0.01 to $1 \mathrm{~mol} \mathrm{~L}^{-1}$ caused the $T_{\text {rot }}(\mathrm{OH})$ and $T_{\text {rot }}\left(\mathrm{N}_{2}\right)$ increase from 3,200 to $4,100 \mathrm{~K}$ and from 1,700 to 2,100 K, as shown in Fig. 8, respectively. For the $\mathrm{HCl}$ concentrations ranging from 0.1 to $1.0 \mathrm{M}$, the excitation temperature and the vibrational temperatures as well as the rotational temperature determined from $\mathrm{OH}$ band were nearly equivalent $(\sim 3,800-4,200 \mathrm{~K})$, while for the solutions containing $0.01 \mathrm{M} \mathrm{HCl}$, the $T_{\text {exc }}(\mathrm{H})$ and $T_{\text {vib }}\left(\mathrm{N}_{2}\right)$ temperatures $(\sim 4,300 \mathrm{~K})$ were higher than the $T_{\text {rot }}(\mathrm{OH}), T_{\text {vib }}(\mathrm{NO})$ and $T_{\text {rot }}(\mathrm{OH})$ temperatures (3,300-3,500 K; Fig. 8).

Generally, the rotational temperatures determined from $\mathrm{OH}$ and $\mathrm{N}_{2}$ band changed in the range from 2,700 to $4,100 \mathrm{~K}$ and from 1,700 to $2,100 \mathrm{~K}$, respectively. Comparable values of the rotational temperatures were noted by Bruggeman et al. [11,22] in the region near the liquid cathode. Similar rotational temperature determined from band of $\mathrm{OH}$ was also measured Nikiforov et al. [26] by LIF and Webb et al. [25] by optical emission spectroscopy (OES) techniques. The vibrational temperature and excitation temperature were consistent with the previous studies $[12,22]$. Throughout all experiments, the $T_{\text {rot }}\left(\mathrm{N}_{2}\right)$ was considerably lower than the $T_{\text {rot }}(\mathrm{OH})$. The difference between these temperatures ranged from 1,000 to $2,100 \mathrm{~K}$. Nevertheless, a relatively good linear correlation $\left(R^{2}=0.85\right)$ was found between $T_{\text {rot }}(\mathrm{OH})$ and $T_{\text {rot }}\left(\mathrm{N}_{2}\right)$. The rotational temperature calculated from band of $\mathrm{NO}$ was equal to $\sim 3,000 \mathrm{~K}$ and was slightly dependent on experimental conditions. It was always observed that $T_{\text {rot }}(\mathrm{OH})>T_{\text {rot }}(\mathrm{NO})>T_{\text {rot }}\left(\mathrm{N}_{2}\right)$. It can be explained by fact that APGD, generated in contact with liquid cathode, mainly operates in saturated water vapour, which contains $\mathrm{H}_{2} \mathrm{O}^{+}$ions [5] and nitrogen diffuses into the plasma from surrounding air [14] and thus may be excited in the "colder" part of plasma outside the central part (core of the glow discharge). The presence of NO in the plasma is probably due to the reaction of high energy states of nitrogen with oxygen [10]. The residual energy from excitation of $\mathrm{N}_{2}$ may be converted into additional rotational energy of $\mathrm{NO}$ and thus the $T_{\text {rot }}(\mathrm{NO})$ may be higher than $T_{\text {rot }}\left(\mathrm{N}_{2}\right)$. The good correlation between $T_{\text {rot }}\left(\mathrm{N}_{2}\right)$ and $T_{\text {rot }}(\mathrm{OH})$ may also indicate that heat transfer from central parts of plasma (core of glow discharge) to "colder" parts can play an important role in the distributions of rotational temperatures in the near cathode region.

Generally, within the uncertainties of the temperature measurements, the vibrational temperatures measured in this work were equilibrated, that is, $T_{\mathrm{vib}}\left(\mathrm{N}_{2}\right) \approx T_{\mathrm{vib}}(\mathrm{OH}) \approx$ $T_{\text {vib }}(\mathrm{NO})$ for electrode gaps larger than $2.5 \mathrm{~mm}$ and $\mathrm{HCl}$ concentrations larger than $0.1 \mathrm{~mol} \mathrm{~L}^{-1}$. The rotational temperature determined from band of $\mathrm{OH}$ was consistent with the vibrational temperature calculated from bands of $\mathrm{OH}$ but differed considerably from $T_{\text {rot }}(\mathrm{NO})$ and $T_{\text {rot }}\left(\mathrm{N}_{2}\right)$. Finally, for $\mathrm{HCl}$ concentrations in the range $0.1-1.0 \mathrm{~mol} \mathrm{~L}^{-1}$ and for gaps $\geq 2.5 \mathrm{~mm}$, the relations between the measured temperatures are as follows (see e.g., Fig. 9):

$$
T_{\mathrm{exc}}(\mathrm{H}) \approx T_{\mathrm{vib}}\left(\mathrm{N}_{2}\right) \approx T_{\mathrm{vib}}(\mathrm{OH}) \approx T_{\mathrm{vib}}(\mathrm{NO}) \approx T_{\mathrm{rot}}(\mathrm{OH})>T_{\mathrm{rot}}(\mathrm{NO})>T_{\mathrm{rot}}\left(\mathrm{N}_{2}\right)
$$




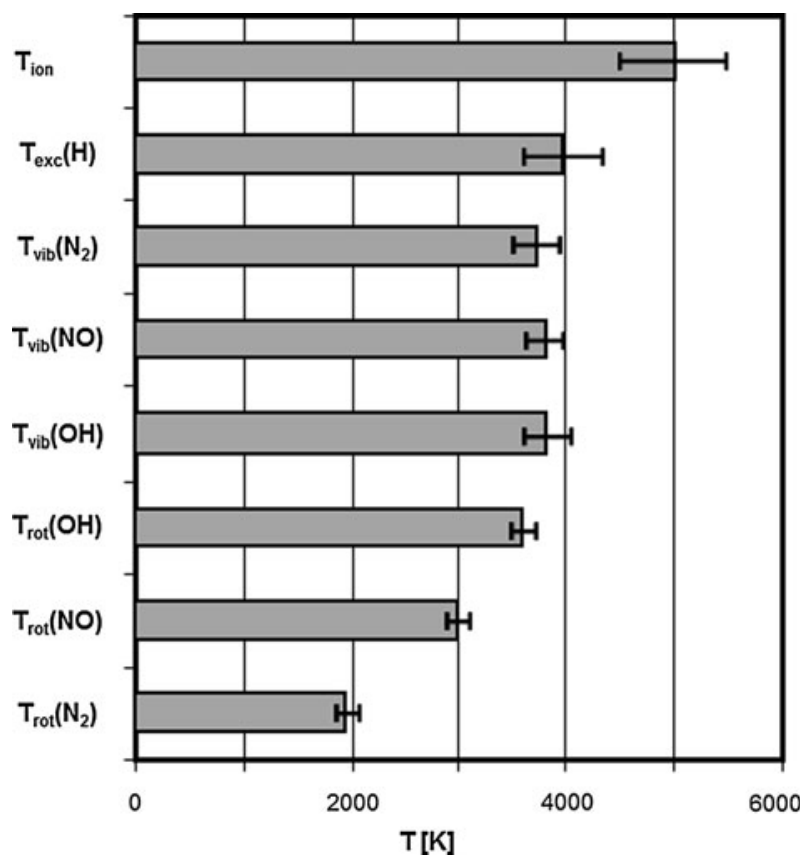

Fig. 9 The distribution of $T_{\text {ion }}, T_{\text {exc }}(\mathrm{H}), T_{\mathrm{vib}}\left(\mathrm{N}_{2}\right), T_{\mathrm{vib}}(\mathrm{NO}), T_{\mathrm{vib}}(\mathrm{OH}), T_{\mathrm{rot}}(\mathrm{OH}), T_{\mathrm{rot}}(\mathrm{NO})$ and $T_{\mathrm{rot}}\left(\mathrm{N}_{2}\right)$ for a gap of $2.5 \mathrm{~mm}\left(0.1 \mathrm{M} \mathrm{HCl}\right.$, solution uptake $\left.1.3 \mathrm{~mL} \mathrm{~min}^{-1}\right)$

The Electron Number Density, Ionization Temperature and Ionization Degree

Electron number density was calculated using the Stark broadening of the $\mathrm{H}_{\beta}$ line (at $486.13 \mathrm{~nm}$ ), employing the following equation, given by Gigososa et al. [32]:

$$
\left(\lambda_{\mathrm{s}} / 4.800\right)=\left(\mathrm{n}_{\mathrm{e}} / 10^{23}\right)^{0.68116}
$$

where $\lambda_{\mathrm{s}}$ is the full with at half maximum (FWHM) in $\mathrm{nm}$ and $\mathrm{n}_{\mathrm{e}}$ is the electron number density in $\mathrm{m}^{-3}$.

The experimental profile of the $\mathrm{H}_{\beta}$ line was fitted using the Voigt algorithm, for deconvolution of a Lorentzian and a Gaussian line profile. This was done using the Galactic Grams/32 computer program. In order to measure the Stark broadening precisely, the $\mathrm{H}_{\beta}$ half width was corrected to account for Van der Waals broadening [22]. Based on the standard deviation, the uncertainty of $\mathrm{n}_{\mathrm{e}}$ was estimated to be up to $10 \%$.

The APGD plasma is not in the equilibrium state. However, at the assumption of the partial LTE state, the ionization temperature may be evaluated for the investigated plasma using the Boltzmann-Saha equation. A similar procedure was recently applied for the determination of the ionization temperature in atmospheric pressure glow discharges generated in air [20] and He [33], and an atmospheric pressure ICP [27, 34].

The ionization temperature $\left(T_{\text {ion }}\right)$ was determined from the Boltzmann-Saha equation, using the ion to atom emission ratio for magnesium, $\operatorname{Mg}(\mathrm{II}) / \mathrm{Mg}(\mathrm{I})$ [27]:

$$
\left(\frac{I_{i}}{I_{a}}\right)=\left(\frac{g_{i} A_{i} \lambda_{a}}{g_{a} A_{a} \lambda_{i}}\right)\left(\frac{2\left(2 \pi m_{e} k T_{\text {ion }}\right)^{3 / 2}}{n_{e} h^{3}}\right) \exp \left(-\frac{E_{\text {ion }}+E_{i}-E_{a}}{k T_{\text {ion }}}\right) .
$$


Table 3 Spectroscopic constant of $\mathrm{Mg}$ lines applied for the determination of the ionization temperature and degree of ionization [30]

\begin{tabular}{lllllll}
\hline Lines & $\lambda(\mathrm{nm})$ & $g_{\mathrm{i}}$ & $g_{\mathrm{j}}$ & $A_{\mathrm{ji}}\left(10^{8} \mathrm{~s}^{-1}\right)$ & $E(\mathrm{eV})$ & $E_{\mathrm{ion}}(\mathrm{eV})$ \\
\hline Mg II & 279.55 & 2 & 4 & 2.60 & 4.434 & 7.646 \\
$\mathrm{Mg} \mathrm{I}$ & 285.21 & 1 & 3 & 4.91 & 4.346 & \\
\hline
\end{tabular}

here $I$ is the line intensity, $g$ is the statistical weight, $A$ is the transition $\mathrm{n}$ probability, $\lambda$ is the line wavelength, $E$ is the energy of the excited state, and $E_{\text {ion }}$ is the ionization potential. Subscripts " $i$ " and " $a$ " refer to parameters for an ion and an atom, respectively.

A solution of hydrochloric acid spiked with $10 \mu \mathrm{g} \mathrm{mL}^{-1} \mathrm{Mg}$ ions was used and the $\mathrm{Mg}$ II line at $279.55 \mathrm{~nm}$ and $\mathrm{Mg}$ I line at $285.21 \mathrm{~nm}$ were measured (see Table 3) for the determination of the ionization temperature. Similar results of $T_{\text {ion }}$ were obtained, if we used ratio of $\mathrm{Mg}$ II line at 280.27 and $\mathrm{Mg}$ I line at $285.21 \mathrm{~nm}$. The error in the ionization temperature determination was estimated to be $500 \mathrm{~K}$.

The $\mathrm{MgII} / \mathrm{MgI}$ intensity ratio was also applied to calculate the degree of ionization $\left(\alpha_{\mathrm{ion}}\right)$ for magnesium, using the equation [35]:

$$
\log \left(\frac{\alpha_{\text {ion }}}{1-\alpha_{\text {ion }}}\right)=\log \left(\frac{I_{i}}{I_{a}}\right)-\log \left(\frac{g_{i} A_{i} \lambda_{a}}{g_{a} A_{a} \lambda_{i}}\right)-\frac{5040}{T}\left(E_{i}-E_{a}\right)+\log \left(\frac{Z_{i}}{Z_{a}}\right)
$$

The partition functions $(Z)$ for atomic and ionic $\mathrm{Mg}$ were obtained from the polynomial tables given by Irvin [36].

The electron number density and the ionization temperature are presented in Fig. 10. The electron density decreased slightly with the $\mathrm{HCl}$ concentration and with the gap between electrodes. As calculated here, the electron number density was 3.4-6.8 $\times$ $10^{20} \mathrm{~m}^{-3}$, and it was consistent with values obtained from the Stark broadening of the $\mathrm{H}_{\beta}$ line in other atmospheric pressure glow discharge plasmas with liquid electrodes [20-22]. The ionization temperature varied over the range 4,900-5,200 $\mathrm{K}$ and was higher than the measured here excitation and vibrational temperatures, i.e., $T_{\text {ion }}>T_{\text {exc }} \approx T_{\text {vib. Similar }}$ value of the ionization temperature was calculated Gielniak et al. [33] and Webb et al. [20] for the APGD plasma source, generated in helium atmosphere and in the contact with the liquid cathode, respectively. It should be noted, that calculated here the ionization temperature and the electron number density were significantly lower than those reported for
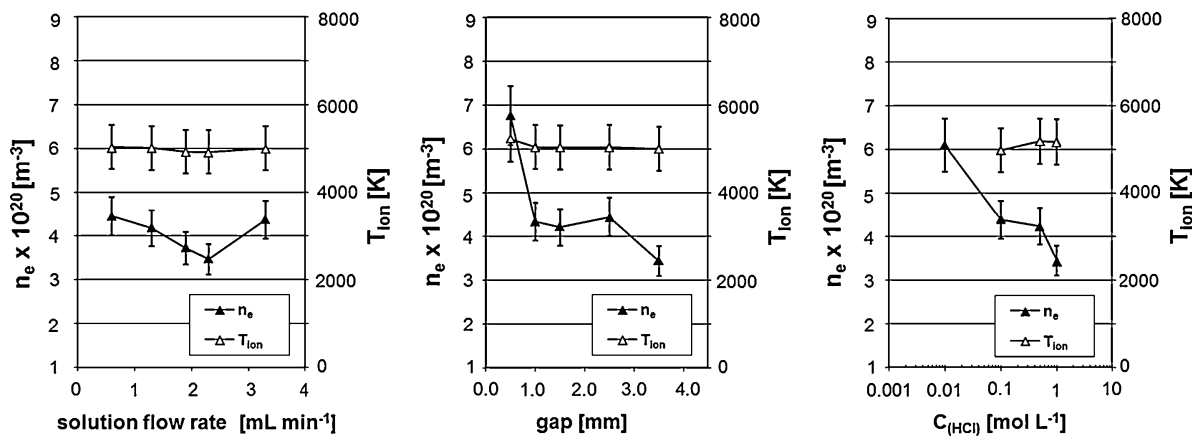

Fig. 10 The electron number density and ionization temperature for the liquid cathode-solid anode system 
an atmospheric pressure ICP source [27, 34]. It is mainly connected with the power of the applied plasma source and conditions of the plasma generation.

The experimental degrees of ionization for $\mathrm{Mg}$ were found to be: $9-14$ and $19-21 \%$ for 0.1 and $0.5-1.0 \mathrm{~mol} \mathrm{~L}^{-1}$ solutions of $\mathrm{HCl}$, respectively. It is almost four-five times lower than in the low power capacitively coupled plasma (CCP) [35] and ICP [27] sources. The ionization degrees $\left(\alpha_{\text {ion }}\right)$ were compared to those calculated from the Saha equation at assumption of plasma equilibrium state. For the ionization temperature equal to $5,000 \mathrm{~K}$ and the electron number density assumed to be $4 \times 10^{20} \mathrm{~m}^{-3}$, the theoretical ionization degree for $\mathrm{Mg}$, (14\%), was consistent with experimental values.

The values of the ionization temperature and the ionization degree are surprisingly low in our investigated plasma source and may indicate that ionization processes play an insignificant role in the production of additional electrons.

\section{Conclusions}

The investigated source with a new construction of the liquid cathode can be operated at lower flow rates (range $0.6-3.2 \mathrm{~mL} \mathrm{~min}^{-1}$ ). A stable atmospheric pressure glow discharge was obtained under these conditions using the electrode gap and the concentration of $\mathrm{HCl}$ within $0.5-3.5 \mathrm{~mm}$ and $0.01-1 \mathrm{~mol} \mathrm{~L}^{-1}$, respectively. The burning voltage in the range of $1,100-1,700 \mathrm{~V}$ and the current equal to $20 \mathrm{~mA}$ was applied to generate stable APGD plasma. The emission spectra of glow discharges were dominated by $\mathrm{OH}, \mathrm{N}_{2}, \mathrm{H}, \mathrm{NH}, \mathrm{NO}$ and $\mathrm{O}$ species. Strong $\mathrm{Mg}$ atomic lines were also observed. Weak ionic lines (Mg II) could be measured, but other ionic species as $\mathrm{N}_{2}{ }^{+}$emission bands and $\mathrm{O}$ II lines were not observed Experimental parameters, such as the solution flow rate, the size of the gap between electrodes, and the concentrations of $\mathrm{HCl}$, significantly affected the observed emission intensities. An increase in solution uptake and in concentration of $\mathrm{HCl}$ caused a growth of $\mathrm{OH}, \mathrm{H}, \mathrm{O}$ and $\mathrm{N}_{2}$ intensities. Maximum spectral intensities were observed for a gap of $2.5 \mathrm{~mm}$ between the solid anode and the water surface.

The excitation, vibrational and rotational temperatures changed with experimental conditions. The $\mathrm{H}$ excitation temperature, the $\mathrm{N}_{2}$ vibrational temperature and the $\mathrm{OH}$ rotational temperature varied from 3,100 to $4,200 \mathrm{~K}$, from 3,100 to $4,600 \mathrm{~K}$ and from 2,700 to $4,100 \mathrm{~K}$, respectively. For selected conditions (gap $\geq 2.5 \mathrm{~mm}, \mathrm{HCl}$ concentration $\left.\geq 0.1 \mathrm{~mol} \mathrm{~L}^{-1}\right)$, some measured temperatures were consistent $(3,800-4,200 \mathrm{~K})$, and $T_{\text {exc }}(\mathrm{H}) \approx T_{\text {vib }}\left(\mathrm{N}_{2}\right) \approx T_{\text {vib }}(\mathrm{OH}) \approx T_{\text {vib }}(\mathrm{NO}) \approx T_{\text {rot }}(\mathrm{OH})$ within the range of experimental uncertainties of the temperature measurement. The $\mathrm{N}_{2}$ and NO rotational temperatures were considerably lower $(\sim 1,700-2,100 \mathrm{~K} ; \sim 3,000 \mathrm{~K}$ respectively), while the ionization temperature was higher ( $\sim 4,900-5,200 \mathrm{~K})$. The relation between the ionization, excitation, vibrational and rotational temperatures followed:

$$
T_{\text {ion }}>T_{\text {exc }}(\mathrm{H}) \approx T_{\text {vib }} \approx T_{\text {rot }}(\mathrm{OH})>T_{\text {rot }}(\mathrm{NO})>T_{\text {rot }}\left(\mathrm{N}_{2}\right) .
$$

The electron number density and ionization degree of $\mathrm{Mg}$ changed over the range $(3.4-6.8) \times 10^{20} \mathrm{~m}^{-3}$ and $9-21 \%$, respectively.

For comparison, in an atmospheric pressure ICP the electron density is one to two orders higher, the $\mathrm{Mg}$ ionization degree reaches $95-99 \%$ while the excitation and ionization temperatures are usually between 5,000 and 10,000 K [34], so the APGD plasma is much more far from the LTE state than the ICP. However, the results indicate that deviations from local thermal equilibrium are not large and rather depend on plasma generation conditions. 
Our results are comparable to other temperature measurements for similar types of discharges generated in the contact with liquid electrodes. Differences between values reported in the literature are likely caused by different conditions of the plasma generation.

Open Access This article is distributed under the terms of the Creative Commons Attribution Noncommercial License which permits any noncommercial use, distribution, and reproduction in any medium, provided the original author(s) and source are credited.

\section{References}

1. Miclea M, Franzke J (2007) Plasma Chem Plasma Process 27:205-224

2. Webb MR, Andrade FJ, Hieftje GM (2007) J Anal At Spectrom 22:766-774

3. Shaltout A (2006) Microchim Acta 155:447-452

4. Kim HJ, Lee JH, Kim MY, Cserfalvi T, Mezei P (2000) Spectrochim Acta B 55:821-829

5. Mezei P, Cserfalvi T (2007) Appl Spectrosc Rev 42:573-604

6. Richmonds C, Sankaran RM (2008) Appl Phys Lett 93:131501

7. Maximov AI, Khlustova AV (2007) Surf Coat Technol 201:8782-8788

8. Malik MA, Ghaffar A, Malik SA (2001) Plasma Sources Sci Technol 10:82

9. Nakano T (2007) IEEE T Dielec El In 14:1081-1087

10. Sugama C, Tochikubo F, Uchida S (2006) Jpn J Appl Phys 45:8858-8863

11. Bruggeman P, Liu J, Degroote J, Konig MG, Vierendeels J, Leys C (2008) J Phys D Appl Phys 41: 215201

12. Titov VA, Rybkin VV, Maximov AI, Choi H-S (2005) Plasma Chem Plasma Process 25:503-518

13. Titov VA, Rybkin VV, Smirnov SA, Kulentsan AL, Choi H-S (2006) Plasma Chem Plasma Process 26:543-555

14. Cserfalvi T, Mezei P, Csillag L (2005) J Phys D Appl Phys 38:2804

15. Verreycken T, Schram DC, Leys C, Bruggeman P (2010) Plasma Sources Sci Technol 19:045004

16. Chen Q, Sato K, Yu-ichiro T, Shirai H (2008) J Phys D Appl Phys 41:175212

17. Shirai N, Nakazawa M, Ibuka S, Ishii S (2009) Jpn J Appl Phys 48:036002

18. Cserfalvi T, Mezei P (1996) Fresenius J Anal Chem 355:813-819

19. Cserfalvi T, Mezei P (2005) J Anal At Spectrom 20:939-944

20. Webb MR, Chan GCY, Andrade FJ, Gamez G, Hieftje GM (2006) J Anal At Spectrom 21:525-530

21. Wilson A, Staack D, Farouk T, Gutsol A, Fridmann A, Farouk B (2008) Plasma Sources Sci Technol 17:045001

22. Bruggeman P, Ribel E, Maslani A, Degroote J, Malesevic A, Rego R, Vierendeels J, Leys C (2008) Plasma Sources Sci Technol 17:025012

23. Machala Z, Janda M, Hensel K, Jedlovský I, Leštinská L, Foltin V, Martišovitš V, Morvová M (2007) J Mol Spectrosc 243:194-201

24. Mezei P, Cserfalvi T, Kim HJ, Mottleb MA (2001) Analyst 126:712-714

25. Webb MR, Andrade FJ, Gamez G, McCrindle R, Hieftje GH (2005) J Anal At Spectrom 20:1218-1225

26. Nikiforov A, Xiong Q, Britun N, Snyders R, Lu XP, Leys C (2011) Appl Phys Express 4:026102

27. Borkowska-Burnecka J, Lesniewicz A, Zyrnicki W (2006) Spectrochim Acta B 61:579-587

28. Luque J, Crosley DR (1999) LIFBASE: database and spectral simulation (version 1.5). SRI International Report MP 99-009

29. Laux CO (2002) Radiation and nonequilibrium collisional-radiative models. In: Fletcher D, Charbonnier J-M, Sarma GSR, Magin T (eds) von Karman Institute Lecture Series 2002-2007 physico-chemical modeling of high enthalpy and plasma flows. Rhode-Saint-Genèse, Belgium

30. NIST Atomic Spectra Database. http://www.physics.nist.gov/PhysRefData/ASD/index.html

31. Lofthus A, Krupenie PH (1977) J Phys Chem Ref Data 6:113-307

32. Gigososa MA, Gonzaez MA, Cardenoso V (2003) Spectrochim Acta B 58:1489-1504

33. Gielniak B, Fiedler T, Broekaert JAC (2011) Spectrochim Acta B 66:21-27

34. Engelhard C, Chan GCY, Gamez G, Buscher W, Hieftje GM (2008) Spectrochim Acta B 63:619-626

35. Rahman M, Blades MW (2000) J Anal At Spectrom 15:1313-1319

36. Irwin AW (1981) Astrophys J Suppl Ser 45:621-633 